\title{
Enantiomeric recognition of amino acid ester salts by $\beta$-cyclodextrin derivatives: an experimental and computational study
}

\author{
Michal Řezanka, ${ }^{a *}$ Ivan Stibor, ${ }^{a}$ Murat Azizoglu, ${ }^{b}$ Yilmaz Turgut, ${ }^{\text {* }}$ Necmettin \\ Pirinccioglu ${ }^{b}$ \\ ${ }^{a}$ Institute for Nanomaterials, Advanced Technologies and Innovation, Technical University of \\ Liberec, Studentská 2, 46117 Liberec 1/Czech Republic \\ ${ }^{b}$ University of Dicle, Faculty of Science, Department of Chemistry, \\ TR-21280, Diyarbakir, Turkey \\ E-mail: michal.rezanka@tul.cz; yturgut@dicle.edu.tr
}

DOI: http://dx.doi.org/10.3998/ark.5550190.p009.657

\begin{abstract}
$\beta$-cyclodextrin derivatives bearing benzoyl ( $\beta$-CD-1) and naphthoyl ( $\beta$-CD-2) moieties have been synthesized from salicylic acid and 3-hydroxy-2-naphthoic acid by a convenient method in $60 \%$ and 58\% yields, respectively, and were tested for enantiomeric recognition of amino acid ester derivatives. Their ability to discriminate between various L-/D- amino acid methyl ester hydrochloride salts was examined using the ${ }^{1} \mathrm{H}$ NMR titration method in DMSO- $d_{6}$ at $25{ }^{\circ} \mathrm{C}$. $\beta$ CD-2 produced a fairly good discrimination of tryptophan ester salts with a binding constant of $4041 \mathrm{M}^{-1}$ for L-salt compared with $2864 \mathrm{M}^{-1}$ for D-salt, which corresponds to a difference of $0.21 \mathrm{kcal} \mathrm{mol}^{-1}$ in binding free energies. The binding free energies obtained from molecular dynamic calculation by $\mathrm{MM} / \mathrm{PB}(\mathrm{GB}) \mathrm{SA}$ are consistent with those obtained from the experimental results.
\end{abstract}

Keywords: Beta-cyclodextrin derivatives, enantiomeric discrimination, ${ }^{1} \mathrm{H}$ NMR titration, molecular dynamic calculations, MM-PB(GB)SA

\section{Introduction}

Cyclodextrins (CDs) are cyclic polysaccharides usually made up of six to eight D-glucose units $(\alpha, \beta, \gamma-\mathrm{CD})$ linked at the $\mathrm{C}_{1}$ and $\mathrm{C}_{4}$ carbon atoms by $\alpha-1,4$-glycosidic bonds. Because of their hydrophilic exteriors and hydrophobic cavities, they can form inclusion complexes with a wide range of guest molecules with a suitable shape and size in water like the hydrophobic pockets in enzymes, and catalyse or promote organic reactions through weak interactions between CDs and substrate molecules $^{1,2}$. From the various types of cyclodextrins, $\beta$-cyclodextrin is widely used 
since it is readily available and can accommodate a wide range of guest molecules because of its suitable cavity.

Molecular recognition of substrates by cyclodextrins occurs by noncovalent interactions in the hydrophobic cavity of the water-soluble, cyclic sugar oligomers. Some modified cyclodextrins have successfully been employed for enantiomer separations in several areas of science and technology ${ }^{3,4}$. The inclusion complex of host-guest systems serves our understanding of the cooperation of several weak forces working between a receptor and substrate, which include dipole-dipole, electrostatic, van der Waals, hydrogen bonding, and hydrophobic interactions 5 .

Enantiomeric recognition of chiral amino acids by synthetic and natural host compounds is a good example of one of the most challenging subjects in modern host-guest chemistry ${ }^{6}$, because host-guest chiral recognition plays an important role in biological processes, and asymmetric catalytic reactions ${ }^{7}$. A number of synthetic model compounds have been designed and synthesized as a chiral host molecule that help chemists understand the basis of the mechanism of host-guest complexations and their chiral recognition. Although significant advances in modelling techniques and the comparative simplicity of the host-guest system have been achieved, we still need to understand the molecular recognition at an atomic level and interpret experimental data by using computational tools and to ultimately help the design of new hosts for targeted molecular guests. Molecular dynamic simulations (MD) have been employed as current methods for understanding molecular recognition processes occurring in organisms at an atomic level, and consequently free energy calculations, initially developed for biological systems, have become a powerful tool in estimating quantitatively molecular interactions in hostguest chemistry. Nevertheless, they have also been applied to supramolecular systems of organic structures $^{8,9}$, even in predicting chiral discrimination ${ }^{10,11}$.
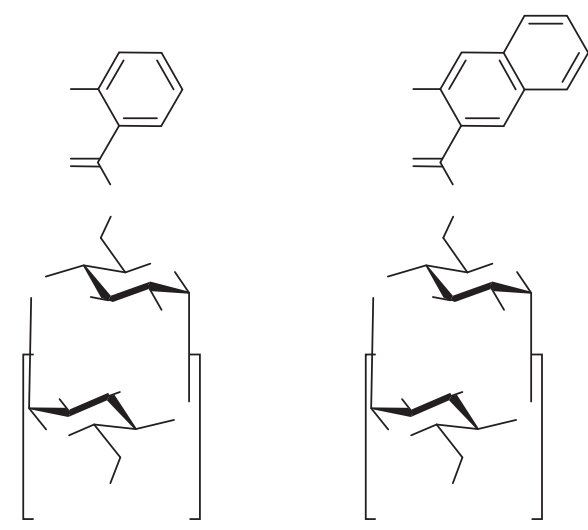

Figure 1. Structure of $C D$ derivatives $\beta-C D-1$ and $\beta-C D-2$. 
The molecular mechanic-Poisson-Boltzmann (Generalized Born) surface area $[\mathrm{MM} / \mathrm{PB}(\mathrm{GB}) \mathrm{SA}]$ is one of the most valuable methods, ${ }^{12}$ which has successfully been applied to estimate the binding free energies of different biological systems. ${ }^{13}$

The present study reports the synthesis of two $\beta$-cyclodextrin derivatives bearing benzo ( $\beta$ CD-1) and naphtho ( $\beta$-CD-2) moieties from salicylic acid and 3-hydroxy-2-naphthoic acid, respectively (Figure 1), and investigates their inclusion complexation behaviour with L/D-amino acid ester salt derivatives (LeuOMe.HCl, PheOMe.HCl, TrpOMe.HCl) (Figure 2) by the ${ }^{1} \mathrm{H}$ NMR titration method in DMSO- $d_{6}$ at $25{ }^{\circ} \mathrm{C}$. Molecular dynamic calculations were also applied to estimate binding free energies for the complexes using MM-PB(GB)SA.

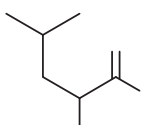

D-LeuOMe.HC

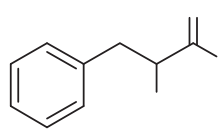

D-PheOMe. $\mathrm{HCl}$

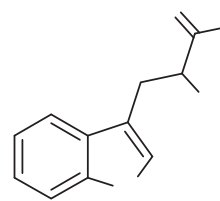

D-TrpOMe. $\mathrm{HCl}$

Figure 2. Amino acid ester salts used as the guest.

\section{Result and Discussion}

\section{Synthesis}

At the outset $6^{\mathrm{A}}$-deoxy- $6^{\mathrm{A}}$-amino- $\beta$-cyclodextrin was prepared via $6^{\mathrm{A}}$-tosy ${ }^{16}$ and $6^{\mathrm{A}}$-deoxy- $6^{\mathrm{A}}$ azido derivatives according to the previously described procedures. ${ }^{17} 6^{\mathrm{A}}$-deoxy- $6^{\mathrm{A}}$-amino- $\beta$ cyclodextrin was used to prepare novel $\beta$-CD-1 and previously synthesized $\beta$-CD-2. ${ }^{15}$ As expected, the reactions proceeded uneventfully to furnish the desired products in yields of $60 \%$ and $58 \%$, respectively (Scheme 1). 

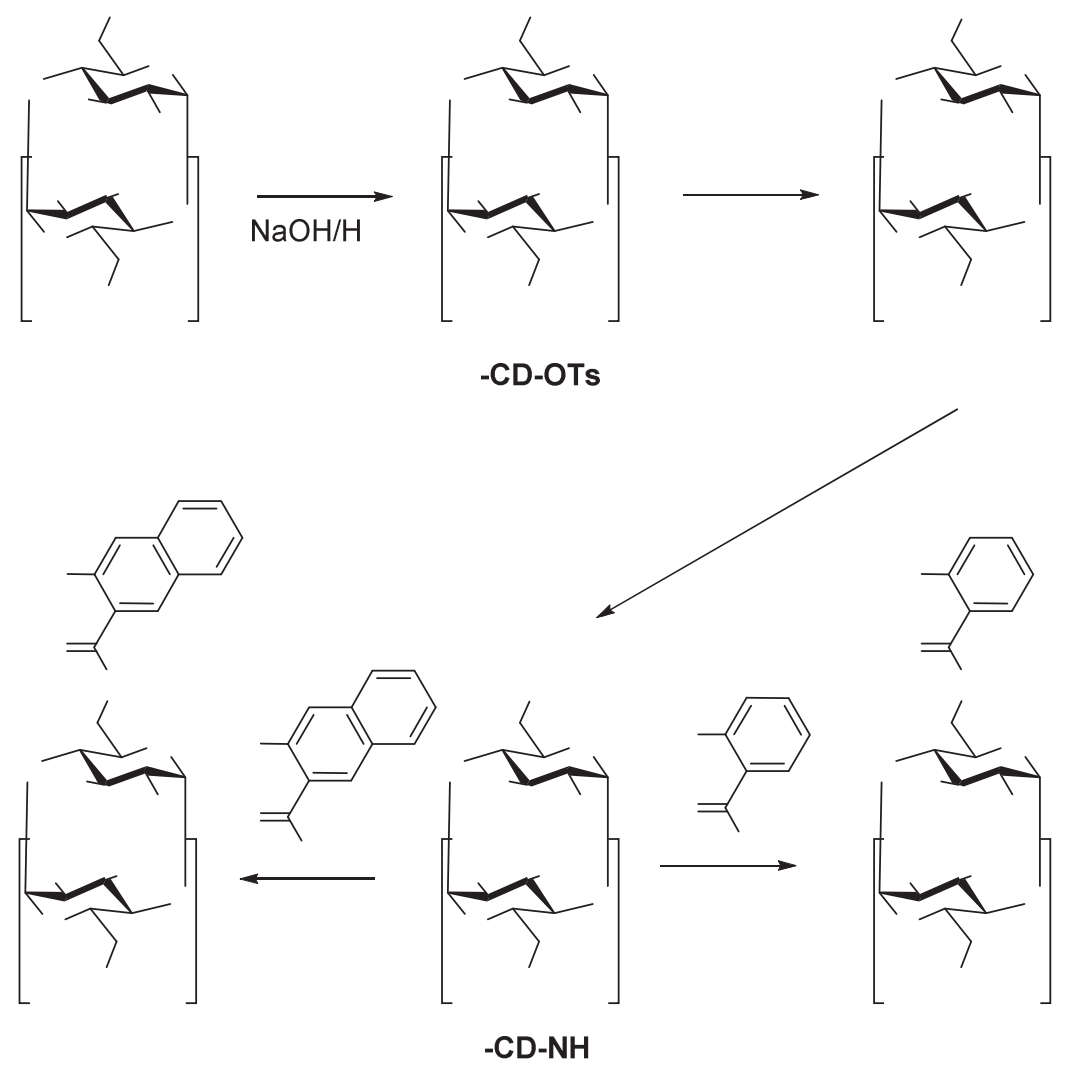

Scheme 1. Synthesis of $\beta-C D-1$ and $\beta-C D-2$.

\section{Enantiomeric recognition}

Amino acid ester salts are widely used in enantiomeric recognition studies for three reasons: (i) ammonium salts form stronger hydrogen bonds than amines, which increases enantioselectivity, (ii) ammonium salts containing an aromatic moiety enable cation- $\pi$ interactions, (iii) the ester moiety in amino acid ester salts contributes to the strength of hydrogen bonding due to its acceptor property and if a proton exists in the macrocycle it also contributes to enantiomeric recognition by forming a hydrogen bond with it.

NMR has become a routinely used tool for the study of host-guest supramolecular chemistry, and there are now hundreds of reports on studies where NMR titration was used to measure intermolecular association. ${ }^{31,32}$ When macrocycles absorb different frequencies in free and complexed states, the differences in chemical shifts in the NMR spectra may suffice for an estimation of the thermodynamics of enantiomeric recognition. In NMR titration experiments, the addition of varying concentrations of guest molecules results in a gradual shifting of several chemical signals upfield or downfield. 
Typical ${ }^{1} \mathrm{H}$ NMR spectral changes upon the addition of amino acid ester salts to a modified cyclodextrin solution are shown in Figure 3.
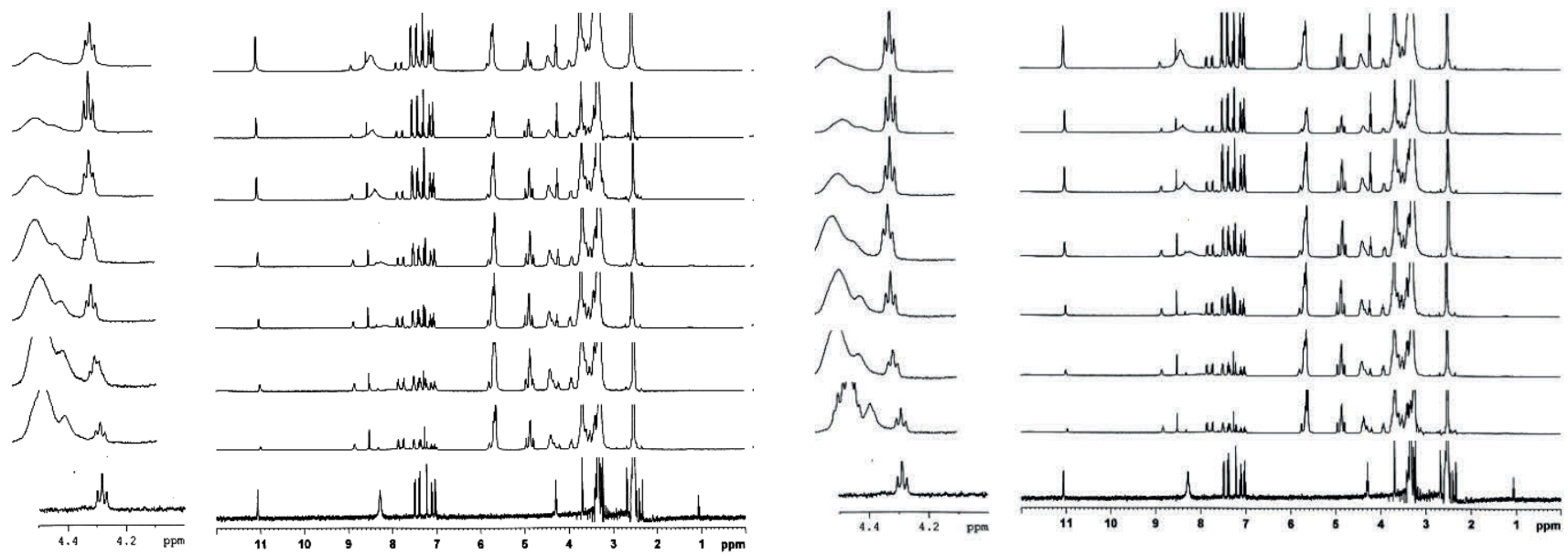

Figure 3. ${ }^{1} \mathrm{H}$ NMR spectral changes in chiral $\beta$-CD-2 $(4.40 \mathrm{mM})$ upon the addition of DTrpOMe.HCl (left) and L-TrpOMe. $\mathrm{HCl}$ (right) in DMSO- $d_{6}$ at $25^{\circ} \mathrm{C}$.

These results indicate the formation of an inclusion complex between modified cyclodextrins and amino acid ester salts with a 1:1 stoichiometry, which was confirmed by a Job plot (Figure 4).

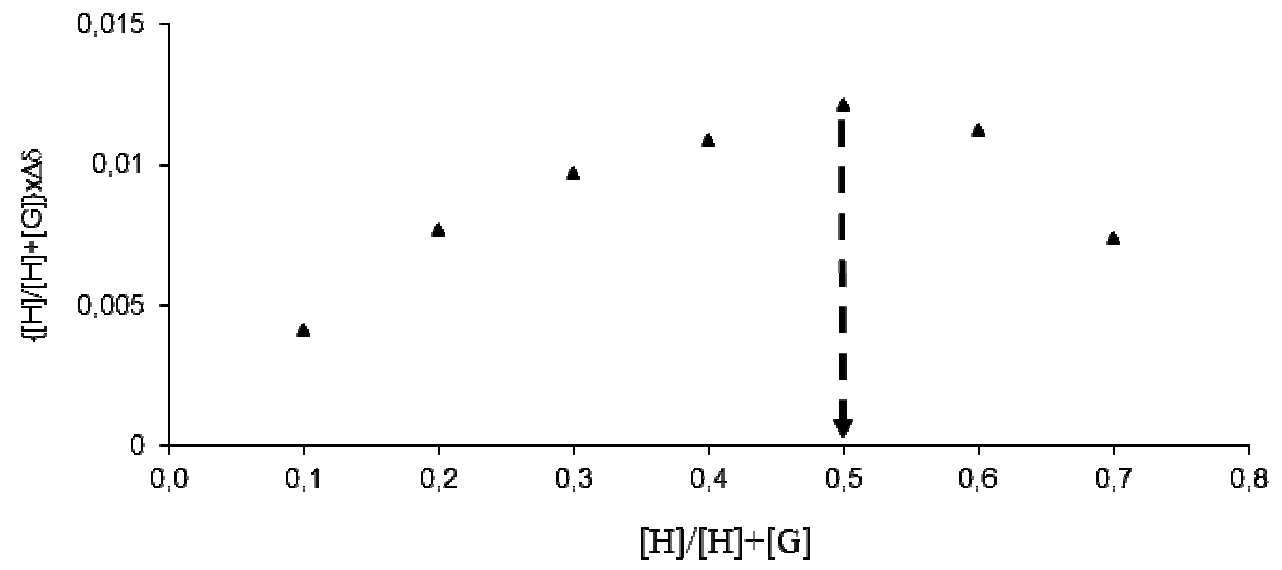

Figure 4. Job plot for the complex of L-PheAlaOMe.HCl with $\beta$-CD-2.

The determination of binding constants for chiral host-guest interaction provides information about the capability of hosts to recognize enantiomers of the chiral guest under given sets of 
conditions. Correlation of the degree of recognition with the structural features of the CD-guest complexes is essential in understanding the origin of the chiral recognition. The ${ }^{1} \mathrm{H}$ NMR titration technique was employed to calculate the binding constants for each enantiomer of LeuOMe. $\mathrm{HCl}, \mathrm{PheOMe} . \mathrm{HCl}$ and TrpOMe. $\mathrm{HCl}$ methyl ester hydrochloride salts with $\beta$-CD-1 and $\beta$-CD-2 (Table 1). The chemical shift of the $-\mathrm{CH}$ (methine, $\delta=4.3125 \mathrm{ppm}$ ) signal in the amino acid salts was monitored against their concentration. A typical plot for the complexation of $\beta$ CD-2 with L-PheOMe.HCl is shown in Figure 5. The calculated $1 / \Delta \delta$ values are plotted against $1 / \Delta \delta_{\max }$ to give an excellent linear relationship $\left(r^{2}=0.9989\right)$ with a slope of 0.0183 . Although the binding constants are relatively large, the discrimination of the enantiomers by the hosts is too small and the difference especially for leucine is within experimental errors.

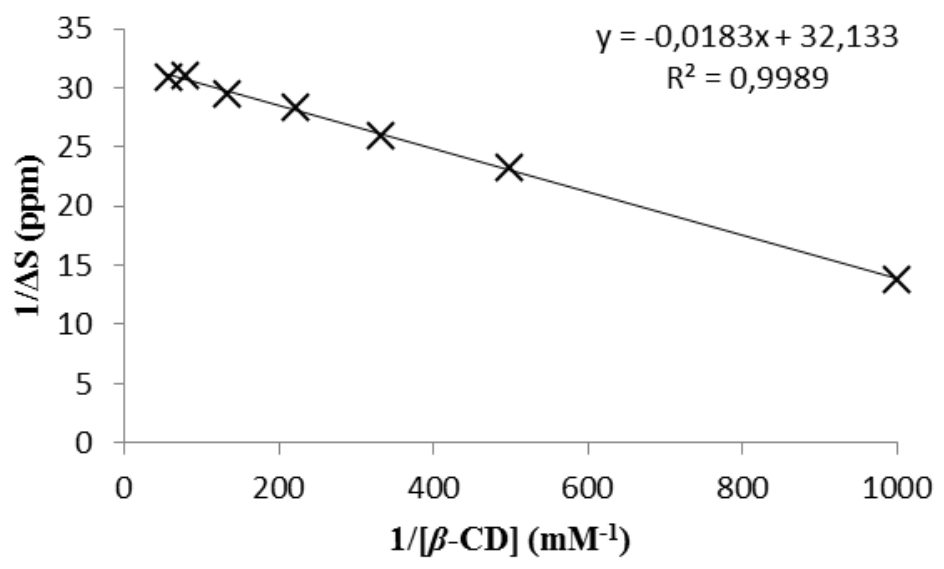

Figure 5. Typical plot of $1 / \Delta \delta$ versus $1 /[\beta-\mathrm{CD}]$ for the complex of $\beta-\mathrm{CD}-2$ with $\mathrm{L}-$ PheAlaOMe.HCl.

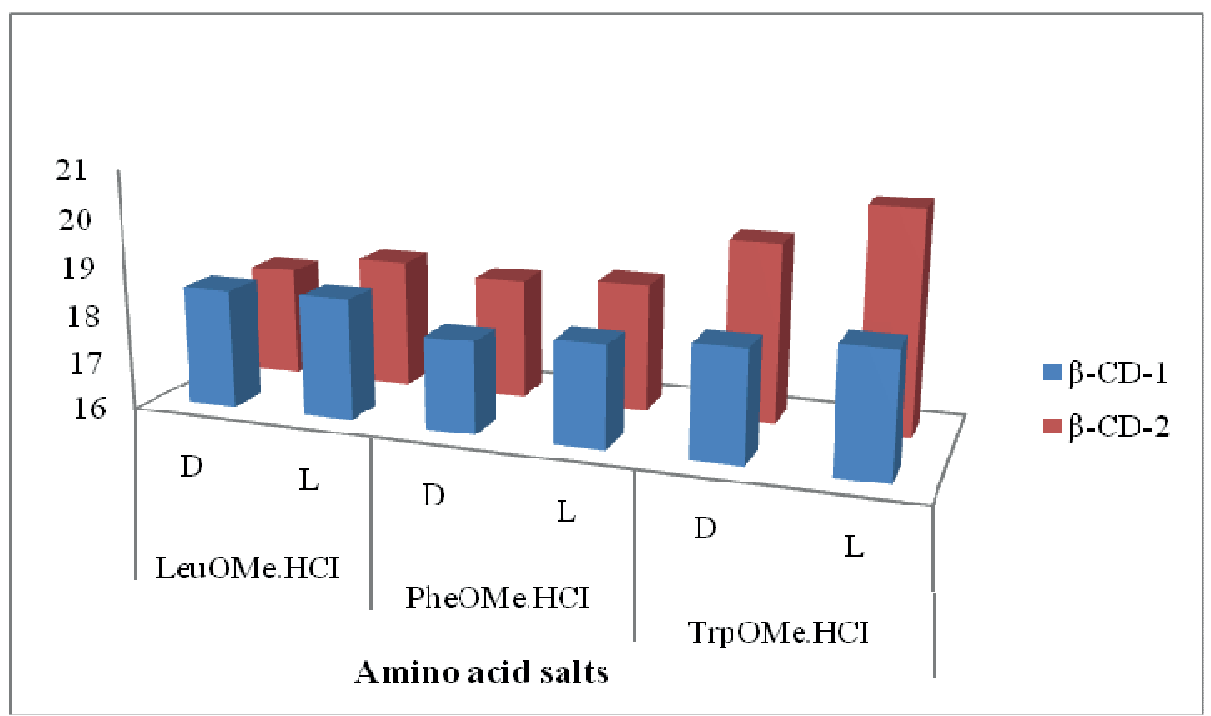

Figure 6. Gibbs free energy changes $\left(-\Delta G^{\circ}\right)$ as a function of amino acids for the inclusion complexes of modified $\beta$-CD-1and $\beta$-CD-2. 
Table 1. Binding constants $\left(K_{\mathrm{a}}\right)$, Gibbs free energy changes $\left(-\Delta G^{0}\right)$ and enantioselectivity $K_{\mathrm{L}} / K_{\mathrm{D}}$ for the complexation of the L-/D-guest with $\beta-\mathrm{CD}-1$ and $\beta-\mathrm{CD}-2$ in DMSO- $d_{6}$

\begin{tabular}{cccccc}
\hline Host & Guests & $K \mathrm{a}\left(\mathrm{M}^{-1}\right)$ & $K_{\mathrm{L}} / K_{\mathrm{D}}$ & $-\Delta G^{\mathrm{o}}\left(\mathrm{kcal} \mathrm{mol}^{-1}\right)$ & $-\Delta \Delta G^{\mathrm{o}}\left(\mathrm{kcal} \mathrm{mol}^{-1}\right)^{*}$ \\
\hline$\beta$-CD-1 & D-LeuOMe.HCl & $1737.17 \pm 0.95$ & 1.02 & $4.41 \pm 0.95$ & -0.02 \\
& L-LeuOMe.HCl & $1764.85 \pm 0.15$ & & $4.43 \pm 0.87$ & \\
& D-PheOMe.HCl & $1376.22 \pm 0.75$ & 1.07 & $4.28 \pm 0.19$ & -0.05 \\
& L-PheOMe.HCl & $1483.78 \pm 0.79$ & & $4.33 \pm 0.53$ & \\
& D-TrpOMe.HCl & $1609.18 \pm 0.30$ & 1.09 & $4.37 \pm 0.97$ & -0.06 \\
& L-TrpOMe.HCl & $1767.78 \pm 0.85$ & & $4.43 \pm 0.28$ & \\
\hline$\beta$-CD-2 & D-LeuOMe.HCl & $1635.02 \pm 0.79$ & 1.16 & $4.38 \pm 0.92$ & -0.09 \\
& L-LeuOMe.HCl & $1906.10 \pm 0.29$ & & $4.47 \pm 0.96$ & \\
& D-PheOMe.HCl & $1755.90 \pm 0.16$ & 1.06 & $4.42 \pm 0.61$ & -0.03 \\
& L-PheOMe.HCl & $1855.56 \pm 0.18$ & & $4.45 \pm 0.30$ & \\
& D-TrpOMe.HCl & $2863.79 \pm 0.31$ & 1.41 & $4.71 \pm 0.91$ & -0.21 \\
& L-TrpOMe.HCl & $4040.75 \pm 0.23$ & & $4.92 \pm 0.29$ & \\
\hline
\end{tabular}

$* \Delta \Delta G^{\mathrm{o}}=-\left(\Delta G_{\mathrm{L}}^{\mathrm{o}}-\Delta G_{\mathrm{D}}^{\mathrm{o}}\right)$

Extensive studies on molecular recognition by cyclodextrins have shown that an important characteristic of complexation is the simultaneous operation of several weak forces working between the guest and CDs, which determine how the size and shape of a guest molecule fit into the host cavity. Data indicate that both $\beta$-CDs form more stable complexes with L-enantiomers of all guests (Table 1). This may be attributed to the strict geometrical complementary relationship between the $\beta$-CD cavity and amino acids. ${ }^{33}$ The results also demonstrate that the host $\beta$-CD-2 forms stronger complexes with amino acid salts compared to those with $\beta$-CD-1, possibly because of the bulkier and more hydrophobic character of the naphtha group compared with the benzyl group. On the other hand, $\beta$-CD-1 shows poor enantioselectivity for three amino acid ester salts. The highest enantioselectivity was observed for tryptophan $\left(K_{\mathrm{L} /} K_{\mathrm{D}}=1.09\right)$. However, $\beta$-CD-2 shows better enantioselectivity for amino acids compared with $\beta$-CD-1, particularly for tryptophan $\left(K_{\mathrm{L} /} K_{\mathrm{D}}=1.41, \Delta \Delta G^{0}=-0.21 \mathrm{kcal} \mathrm{mol}^{-1}\right.$, Figure 6$)$. The larger enantioselectivity found by $\beta$-CD- 2 may be attributed to the difference in the size of the site arms, naphtha and benzyl. It was found that both hosts bind and discriminate tryptophan, possibly due to stronger $\pi-\pi$ interactions between CD (hosts) and Trp (guest) molecules in addition to weaker non-covalent interactions (hydrogen bonding, van der Waals, dipol-dipol etc.). The reason for the better selectivity presented by $\beta$-CD-2 for this guest may be associated with the larger size of napthyl compared with benzyl in $\beta$-CD-1. The better selectivity found for tryptophan by both hosts may be attributed to the indole ring, better fitted to the cavity compared with phenyl and isopropyl in phenylalanine and leucine. It seems that the size and shape of the guest molecule and the structural change of the host molecule administrate the complexation phenomena to some extent. Hence, the induced fit and the geometrical complement between the host and the guest play a 
crucial role in the chiral recognition of amino acid molecules. The stability of the inclusion complex with modified cyclodextrin should depend on the condition of strict size-fit between host and guest.

\section{Computational modelling}

Although significant information has been obtained regarding the stability and selectivity of the complexes of modified $\beta$-CDs with methyl esters of amino acids, one still cannot reach a conclusion about the mode of these complexes and the main driving forces behind the enantioselectivity imposed by these hosts and hence the truer of molecular recognition at an atomic level. Molecular dynamic simulations (MD) have been employed to understand the dynamic behaviour of these complexes and hence the binding energies for each complex were calculated from the dynamic trajectories of $\mathrm{MM} / \mathrm{PB}(\mathrm{GB}) \mathrm{SA}$. The molecular dynamic calculations were performed for both $\mathrm{CDs}$ from $0 \mathrm{~K}$ to $700 \mathrm{~K}$. The reason for MD calculations at higher temperature is to avoid the possible traps of conformers in local minima. RMSD changes obtained for the CDs at $700 \mathrm{~K}$ compared to their starting coordinates as a function of time during the MD are presented in Figure 7. They show that the major conformational fluctuation occurs in the cyclodextrin cavities of $\beta-C D-1$ and $\beta-C D-2$. The conformers with a higher population for each CD are presented in Figure 8. They show both $\beta$-hydroxyl phenyl and naphthyl groups are located perpendicular to the cavity of both hosts. The molecular dynamic calculations were also performed for the complexes of CDs with enantiomers of methyl esters of amino acid salts. RMSD changes obtained for each complexes compared to their starting coordinates as a function of time during the MD are presented in Figure 9. They show that the complexes of salts with both CDs does not experience large conformational changes, except that the complex of leucine salts with CDs have larger RMSD, more underlined with $\beta$-CD-1, possibly due to the large conformational fluctuations of the salts due to weaker binding of the site arm, isopropyl compared with phenyl and indole rings in other salts. It is evident that the receptors do not show large dynamic oscillation (Figure 9).

The lowest energy conformers for each complex of $\beta$-CD-1 and $\beta-C D-2$ with enantiomers of amino acid ester salts obtained from the cluster analyses are superimposed to see the mode of action behind the discrimination. They are displayed in Figures 10. They show that all of the site arms of salts are included in the cavity of $\beta-C D-1$ and $\beta-C D-2$ except for L-leucine where its methyl ester function tends to be located within the cavities of both hosts in an opposite direction to $\beta$-hydroxy phenyl and naphthyl groups. The MD calculations show that the ammonium ion interacts with the carbonyl groups for all the complexes of both hosts (Figure 11).

They also indicate that the indole ring of tryptophan better fits into the cavities of both hosts compared with the phenyl and isopropyl groups in phenylalanine and leucine salts, which is consistent with the experimental observations. Beside atom distance analyses (between methane hydrogen in the salts and C5 in CDs) demonstrate that the ligands are held within the cavity during MD simulations (Figure 11). Consistency with the experimental observations is also found for the discrimination of the enantiomers of these amino acid salts. The binding free 
energy obtained for the D-phenylalanine salt by MM-PBSA (see Table 2) is somehow too large and stands out of the scale obtained for the rest of the enantiomers.
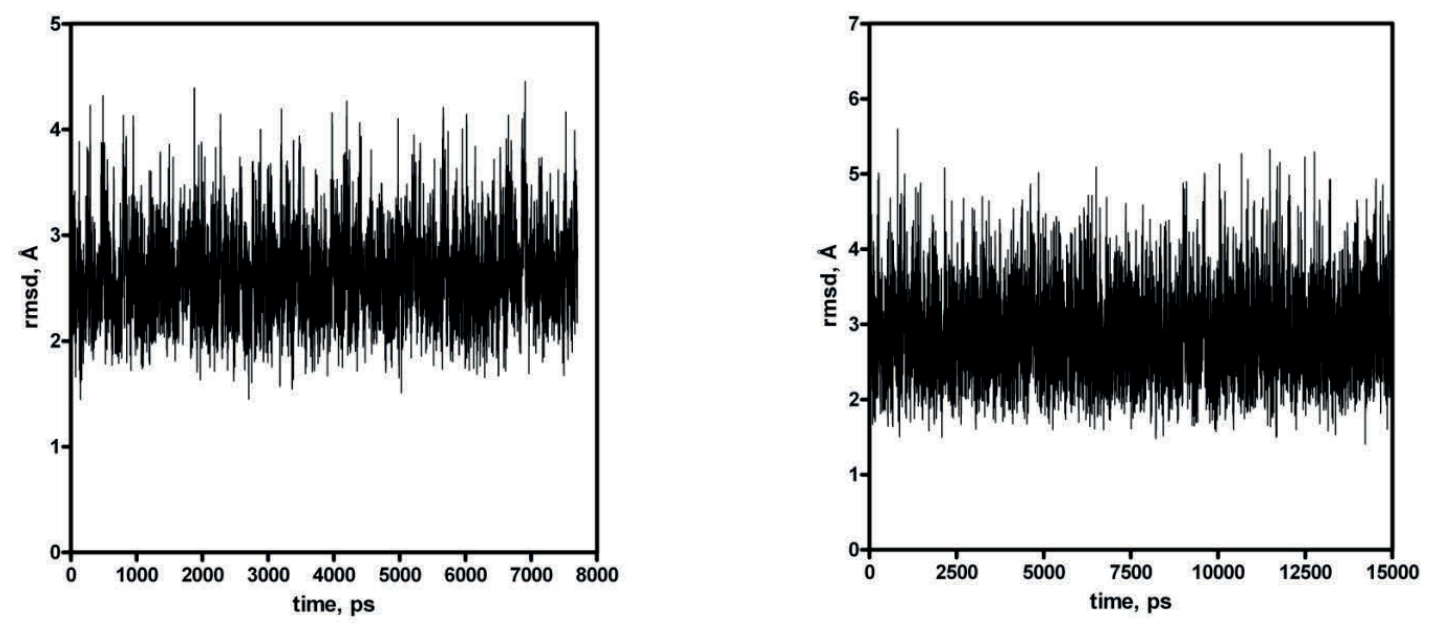

Figure 7. RMSD changes obtained for $\beta$-CD-1 (left) and $\beta$-CD-2 (right) compared to their starting coordinates as a function of time during MD performed at $700 \mathrm{~K}$.
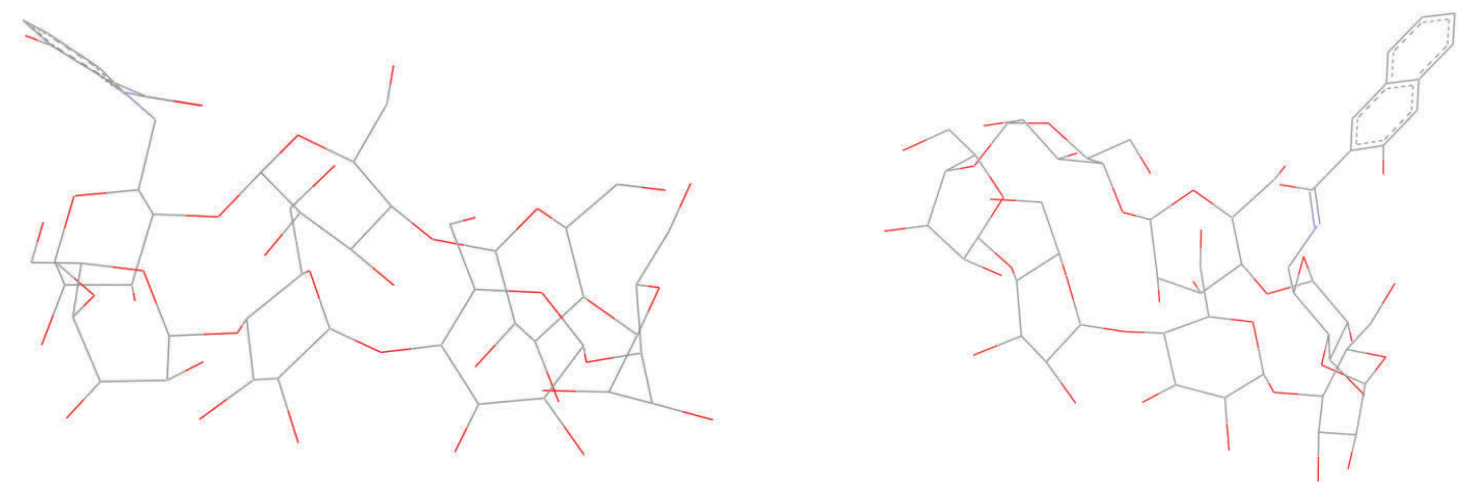

Figure 8. The lowest energy conformers of $\beta$-CD-1 (left) and $\beta$-CD-2 (right). 

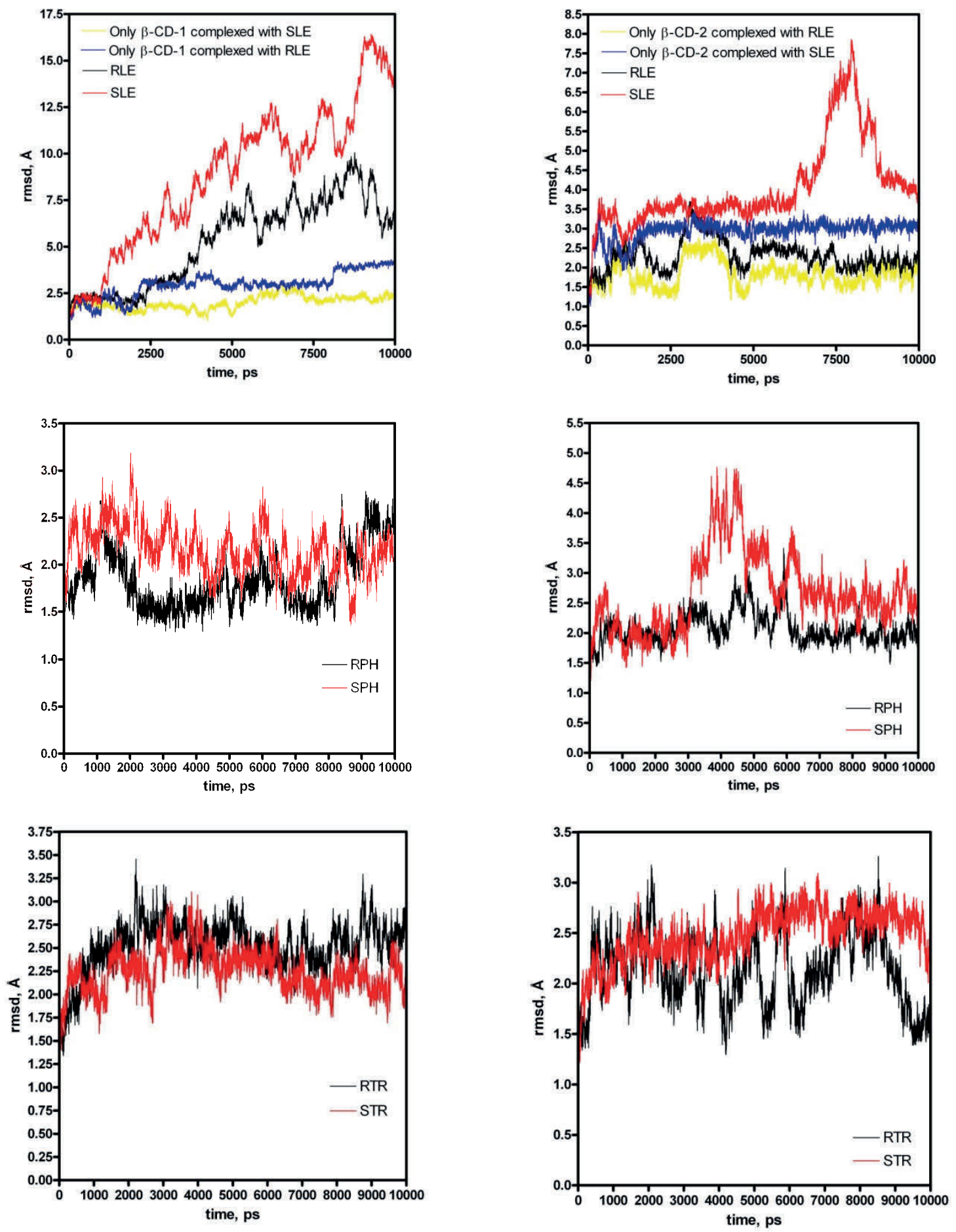

Figure 9. RMSD changes obtained for the complexes of $\beta-C D-1$ (left column) and $\beta$-CD-2 (right column) with amino acid ester salts compared to their starting coordinates as a function of time during MD performed at $298 \mathrm{~K}$. (RLE: D-LeuOMe.HCl; SLE: L-LeuOMe.HCl; RPH: D-PheOMe.HCl; SPH: LPheOMe.HCl; RTR: D-TrpOMe.HCl; STR: L-TrpOMe.HCl) 

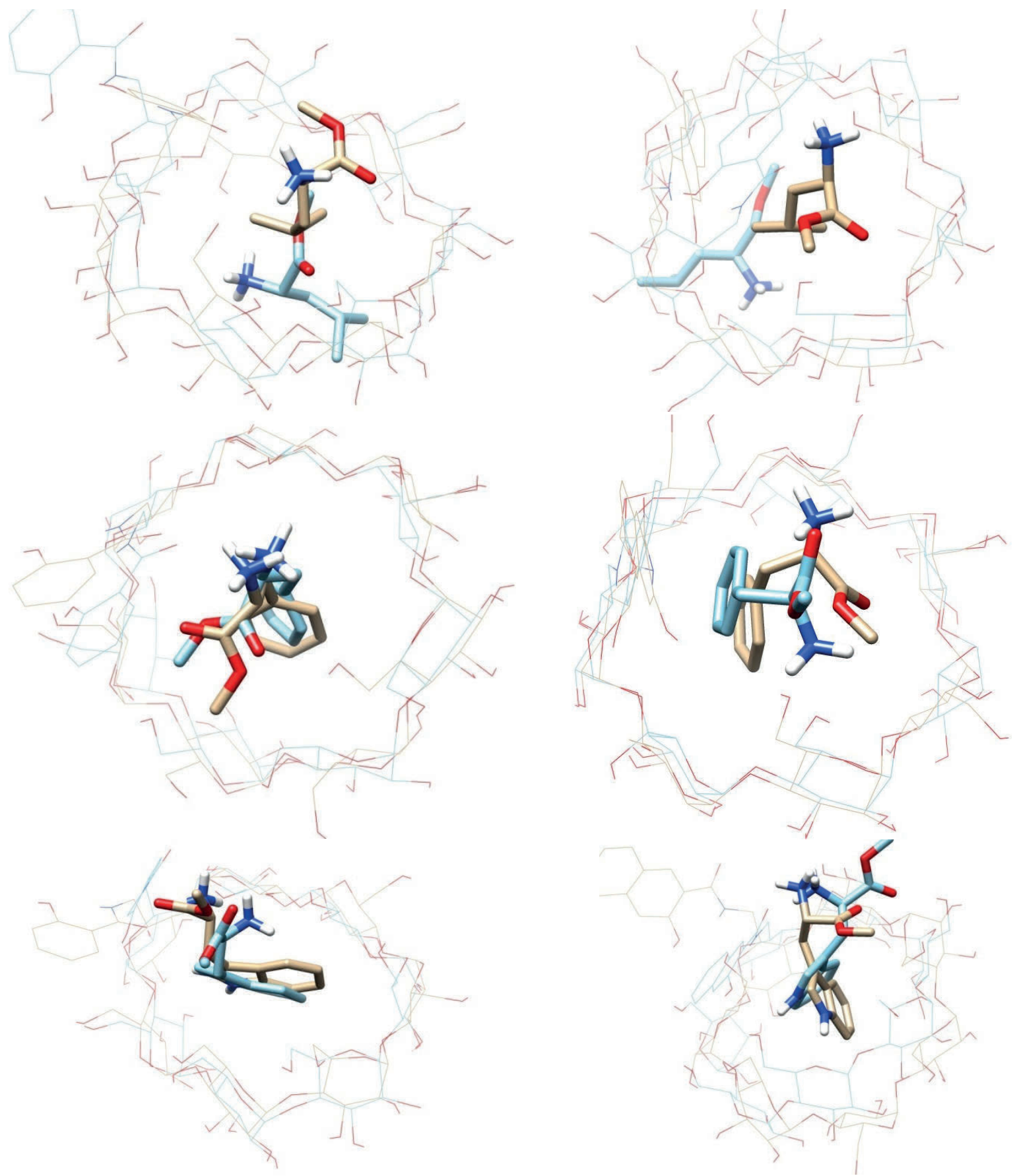

Figure 10. The superimposed lowest energy conformers of $\beta$-CD-1 (right column) and $\beta$-CD-2 (left column) with methyl esters of leucin (top row), phenylalanine (middle row) and tryptophan (bottom row). 

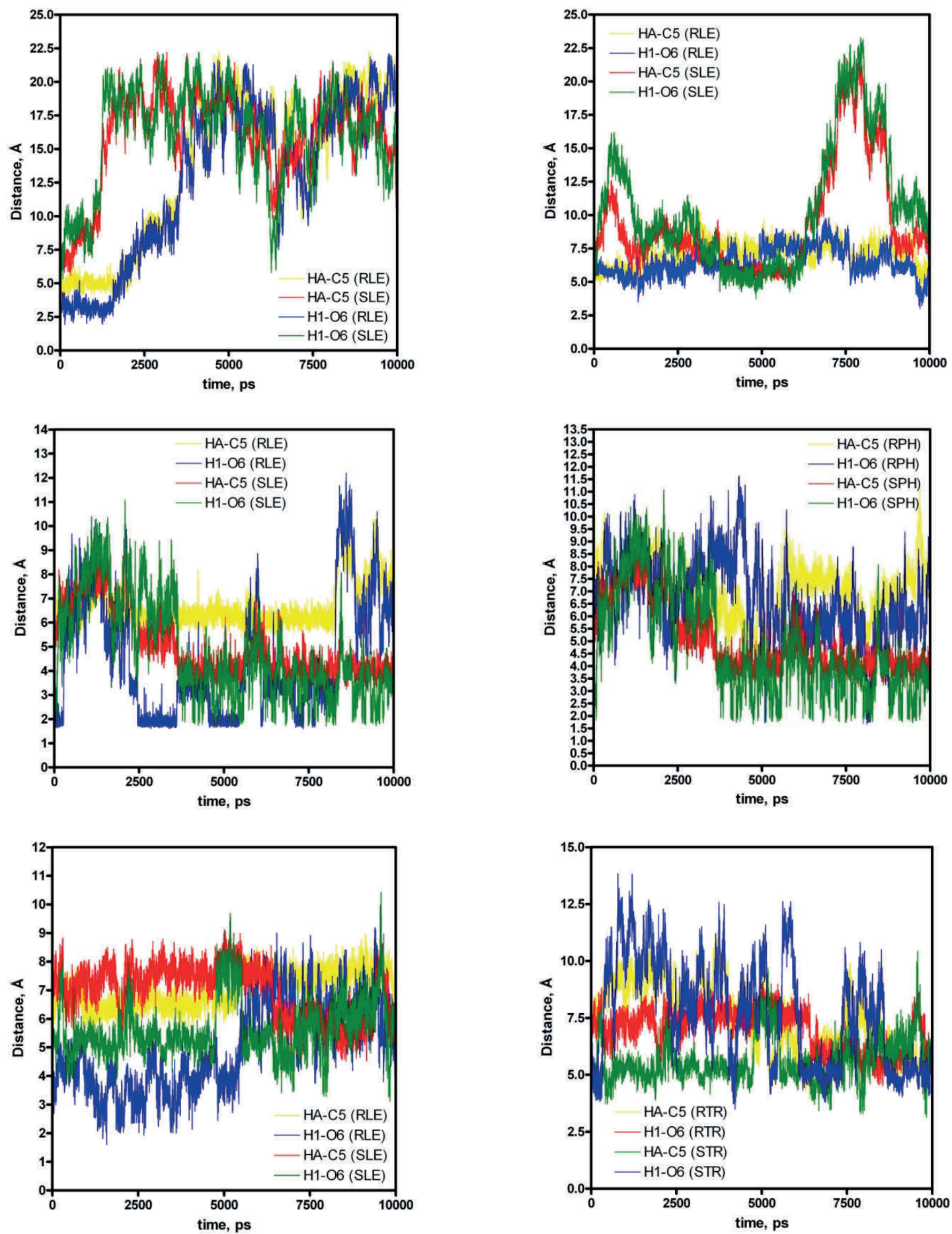

Figure 11. Distances between $\mathrm{CH}$ (HA) in the ligand and (C5) in the host and between one of ammonium hydrogens in the ligand and carbonyl oxygen in the receptor obtained from MD simulations for the complexes of $\beta$-CD-1 (left column) and $\beta-C D-2$ (right column) with amino acid ester salts at 298 K. (RLE: D-LeuOMe.HCl; SLE: L-LeuOMe.HCl; RPH: D-PheOMe.HCl; SPH: L-PheOMe.HCl; RTR: D-TrpOMe.HCl; STR: L-TrpOMe.HCl) 
Table 2. Binding energies obtained from MD calculations by MM-PB(GB)SA for the complexes of $\beta$-CD-1 and $\beta-C D-2$

\begin{tabular}{lccccc}
\hline \multirow{2}{*}{ Hosts } & Ligands & $\Delta \mathrm{G}_{\mathrm{GB}}$ & $\Delta \mathrm{G}_{\mathrm{PB}}$ & $\Delta \Delta \mathrm{G}_{\mathrm{GB}}$ & $\Delta \Delta \mathrm{G}_{\mathrm{PB}}$ \\
\cline { 3 - 6 }$\beta$-CD-1 & D-LeuOMe.HCl & $0.268 \pm 0.051$ & $0.982 \pm 0.018$ & -0.062 & 0.053 \\
& L-LeuOMe.HCl & $0.330 \pm 0.069$ & $0.929 \pm 0.019$ & & \\
& D-PheOMe.HCl & $-6114 \pm 1605$ & $-6114 \pm 1605$ & --- & - \\
& L-PheOMe.HCl & $-14.45 \pm 2.28$ & $-11.88 \pm 3.06$ & & \\
& D-TrpOMe.HCl & $-17.51 \pm 2.44$ & $-15.93 \pm 2.48$ & 1.36 & 0.86 \\
& L-TrpOMe.HCl & $-18.87 \pm 1.98$ & $-16.79 \pm 1.91$ & & \\
\hline \multirow{2}{*}{$\beta-\mathrm{CD}-2$} & D-LeuOMe.HCl & $-9.80 \pm 1.08$ & $-7.60 \pm 1.28$ & -3.27 & -2.29 \\
& L-LeuOMe.HCl & $-6.53 \pm 1.47$ & $-5.31 \pm 2.14$ & & \\
& D-PheOMe.HCl & $-6.99 \pm 1.24$ & $-4.70 \pm 1.39$ & -1.15 & -0.26 \\
& L-PheOMe.HCl & $-5.84 \pm 0.95$ & $-4.44 \pm 1.04$ & & \\
& D-TrpOMe.HCl & $-14.04 \pm 1.78$ & $-12.01 \pm 2.17$ & 3.16 & 6.22 \\
& L-TrpOMe.HCl & $-17.20 \pm 2.43$ & $-18.22 \pm 2.52$ & & \\
\hline
\end{tabular}

\section{Conclusions}

Two novel derivatives of $\beta$-cyclodextrin were prepared and their binding and enantioselective properties for methyl esters of some amino acid hydrochloride salts were investigated by the ${ }^{1} \mathrm{H}$ NMR titration technique. The result indicate that hosts have a significant ability to accommodate all amino acid salts and also that the host bearing the naphtho group has more binding and discrimination ability for the salts compared to the host bearing the benzo group. The molecular dynamic calculations are in agreement with those obtained by experimental observations and also give a detailed picture of complexes at an atomic level. Hence, these results may be useful in the understanding of the biochemical processes occurring in the cell.

\section{Experimental Section}

General. All of the chemicals were reagent grade unless otherwise specified. D- and L-amino acid methyl ester hydrochlorides and $\beta$-cyclodextrin $(\geq 97 \%)$ were obtained from Aldrich Chemical Co. Silica gel 60 (Merck, 0.040-0.063 mm) and silica gel/TLC-sheets (F254) were used for flash column chromatography and TLC. Melting points were determined with a Gallenkamp Model apparatus with open capillaries. Infrared spectra were recorded on a Mattson 1000 FTIR model spectrometer. ${ }^{1} \mathrm{H}(400 \mathrm{MHz})$ and ${ }^{13} \mathrm{C}(100 \mathrm{MHz}) \mathrm{NMR}$ spectra were recorded 
on a Bruker AV400 high performance digital FT-NMR spectrometer. The chemical shifts $(\delta)$ and coupling constants $(J)$ were expressed in parts per million and hertz, respectively.

\section{NMR titration}

A range of stock solutions of the ligands $\left(0-10^{-4} \mathrm{M}\right)$ containing a constant amount of the CDs $\left(10^{-3} \mathrm{M}\right)$ in DMSO- $d_{6}$ was prepared and their ${ }^{1} \mathrm{H}$ NMR spectra (16 scans, sweep width of 20.7 ppm, digital resolution of 18 , pulse angle of $30^{\circ}$, delay time of $1 \mathrm{sec}$ ) were collected at $298 \mathrm{~K}$ at ambient probe temperature and calibrated using tetramethylsilane as an internal reference. The changes in the chemical shift of $-\mathrm{CH}$ (methine) in amino acid methyl ester salts against their concentration were fitted to Equation 4, derived from Equations 1-3. The binding constants of the complexes of D- and L-amino acids ester salts with $\beta-C D-1$ or $\beta-C D-2$ were calculated by the Benesi-Hildebrand method ${ }^{14}$.

$$
\begin{aligned}
& C D+\quad G \quad \frac{k_{1}}{K_{\text {diss }}=k_{1} / k_{-1}=[C D][G] /[[}=3 \\
& {[G]_{\text {tot }}=[G]_{\text {free }}+[G]_{\text {complex }}} \\
& 1 / \Delta \delta=1 /\left(K_{\mathrm{a}} \cdot \Delta \delta_{\max } \cdot[\mathrm{G}]_{\mathrm{tot}}\right)+1 / \Delta \delta_{\max }
\end{aligned}
$$

where $\Delta \delta=\left(\delta_{\mathrm{G}}-\delta_{\mathrm{obs}}\right)$, and $\Delta \delta_{\max }=\left(\delta_{\mathrm{G}}-\delta_{\mathrm{CD}: \mathrm{G}}\right), \Delta \delta_{\max }$ is the difference in chemical shift between the complexed and the free guest at saturation, $[G]_{\text {tot }}$ is the total concentration of guest and $K_{\text {diss }}$ is the dissociation constant between $\mathrm{CD}$ and the guest.

\section{Synthesis of $\beta$-CD-1}

6 $^{\mathbf{A}}$-Deoxy-6 ${ }^{\mathbf{A}}$-((2-hydroxybenzoyl)amino)- $\boldsymbol{\beta}$-cyclodextrin. The synthesis was adapted from a previously published method. ${ }^{15}$ Solutions of $N, N^{\prime}$-dicyclohexylcarbodiimide (91 mg, $0.44 \mathrm{mmol}$ ) in DMF (4 mL) and hydroxybenzotriazole $(68 \mathrm{mg}, 0.44 \mathrm{mmol})$ in DMF (4 ml) were added to a solution of salicylic acid $(61 \mathrm{mg}, 0.44 \mathrm{mmol})$ in $\mathrm{DMF}(5 \mathrm{~mL})$ cooled to $0{ }^{\circ} \mathrm{C}$. The reaction mixture was stirred for 0.5 hours at $0{ }^{\circ} \mathrm{C}$ and a solution of $6^{\mathrm{A}}$-deoxy- $6{ }^{\mathrm{A}}$-amino- $\beta$ cyclodextrin $^{16,17}$ (500 mg, $\left.0.44 \mathrm{mmol}\right)$ in DMF $(17 \mathrm{~mL})$ was added dropwise. The reaction mixture was then stirred for another hour at $0{ }^{\circ} \mathrm{C}$ and 48 hours at room temperature. The reaction was quenched by pouring the mixture into acetone $(300 \mathrm{~mL})$. The precipitate was filtered out and purified by crystallization from water to yield $333 \mathrm{mg}(60 \%)$ of the title compound as a white powder. Mp $228{ }^{\circ} \mathrm{C}$ (decomp.). IR (KBr): 3507, 3280, 3155, 3117, 3058, 1642, 1150, $1030 \mathrm{~cm}^{-1}$. ${ }^{1} \mathrm{H}$ NMR (DMSO- $d_{6}$ ): $\delta 12.39$ (s, $\left.1 \mathrm{H}, \mathrm{Ar}-\mathrm{OH}\right), 8.67$ (s, $1 \mathrm{H},-\mathrm{NH}-$ ), 7.82 (d, J 7.6 Hz, $1 \mathrm{H}$, Ar$H$ ), 7.38 (t, J 7.7 Hz, 1H, Ar-H), 6.94-6.82 (m, 2 H,Ar-H), 5.94-5.51 (m, 14 H, 7 x CD-OH (2), 7 x CD-OH (3)), 4.95-4.75 (m, 7 H, 7 x CD-H (1)), 4.56-4.33 (m, 6 H, 6 x CD-OH (6)), 3.92$3.10(\mathrm{~m}, 42 \mathrm{H}, 7$ x CD- $H(2), 7$ x CD- $H$ (3), 7 x CD- $H$ (4), 7 x CD- $H(5), 14$ x CD- $H(6))$ ppm. ${ }^{13} \mathrm{C}$ NMR (DMSO- $\left.d_{6}\right): \delta=168.61$ (-CONH-), 159.65 (Ar- $\left.C-\mathrm{OH}\right), 133.52(\operatorname{Ar}-C), 128.15(\operatorname{Ar}-C)$, 
118.51(Ar-C), 117.21(Ar-C), 115.56(Ar-C), 102.39-101.88 (7 x CD-C (1)), 84.16-59.91 (7xCD$C$ (2), 7 x CD-C (3), 7 x CD-C (4), 7 x CD- $C$ (5), 7 x CD- $C$ (6)) ppm.

\section{Computational modelling}

All of the molecular dynamic (MD) simulations were conducted using the Assisted Model Building with Energy Refinement (AMBER version 11.0) ${ }^{18}$ suite of programmes on TR-Grid clusters based on Linux (TUBITAK). The structure of $\beta$-cyclodextrin was obtained from the Xray structure (3CGT.pdb) found in the protein data bank (http://www.pdb.org). ${ }^{19}$ The complexes were prepared by manually locating the site chain of each enantiomer into the cavity of the hosts using Discovery Studio Visualizer. ${ }^{20}$ All of the atoms and charges for $\alpha$-D-glucopyranoside units in the CDs were assigned as described in GLYCAM-06. ${ }^{21}$ Atomic partial charges were calculated by AM1-Bcc (Austin model with bond and charge correction ${ }^{22}$ using the antechamber module of AMBER (v11) for the modified residues by the introduction of benzyl and naphtyl amides and ff $99 \mathrm{SB}^{23}$ atom types were assigned for the benzyl and naphthyl parts. Xleap, as implemented in AMBER, was employed to prepare the parameter/topology and coordinate files and to solvate and neutralize the system for MD simulations. The complexes were solvated in a TIP3 ${ }^{24}$ water box, which is a very popular solvation model for molecular dynamic simulations because of its simplicity and computational efficiency, with dimensions of $10 \AA$ from the solute. Ptraj as implemented in AMBER was used for coordinate root-mean squared deviation (RMSD) and atom distance analyses. Three dimensional structures were displayed using Chimera (UCSF). ${ }^{25}$

To test the validity of the employed parameters and also to determine the dynamic behaviour of each host, they were heated from 0 to $700 \mathrm{~K}$ in a vacuum for a period of $15 \mathrm{~ns}$. The complexes in explicit water were minimized in two stages; in the first, the hosts and guest were kept fixed and only the water molecules were allowed to move in 1000 steps (2500 steps with the steepest descent and 2500 steps with the conjugate gradient method, respectively) with a restraint of 500 $\mathrm{kcal} \mathrm{mol}^{-1} \AA^{-2}$. In the second stage, all of the atoms were allowed to move in 2500 steps (1250 steps with the steepest descent and 1250 steps with the conjugate gradient method, respectively). Heating was performed in a canonical ensemble for $200 \mathrm{ps}$ with a restraint of $10 \mathrm{kcal} \mathrm{mol}^{-1} \AA^{-2}$ on the complex. The final simulations, the production phase, were performed for $10 \mathrm{~ns}$ in the canonical ensemble at $300 \mathrm{~K}$ and 1 atm without any restraint. The step size for the entire simulation was 2 fs. A Langevin thermostat and barostat were used for coupling the temperature and pressure. A SHAKE algorithm was applied to constrain all of the bonds containing hydrogen atoms. ${ }^{26}$ The no-bonded cut off was kept at $10 \AA$, and long range electrostatic interactions were treated by the particle mesh Ewald (PME) ${ }^{27}$ method with a fast Fourier transform grid having a spacing of approximately $0.1 \mathrm{~nm}$. Trajectory snapshots were taken every $0.2 \mathrm{ps}$, and were finally used for analysis. The Ptraj module of AMBER was used to obtain root mean square deviation (RMSD) changes during the molecular dynamic simulations, which are presented in GraphPad Prism 4. Cluster analyses were performed using Chimera. ${ }^{25}$ 


\section{MM-PB(GB)SA}

The Molecular Mechanics-Poisson-Boltzmann Surface Area (MM-PBSA)/Molecular MechanicsGeneralized Born Surface Area (MM-GBSA) module of AMBER (v11) was applied to compute the binding free energy $\left(\Delta G_{\text {bind }}\right)$ of each complex. ${ }^{28,29}$ For each complex, a total number of 200 snapshots were extracted from the last $10 \mathrm{~ns}$ of the complex trajectories. In the MM-PB(GB)SA, the binding free energy of a ligand $(\mathrm{L})$ to a receptor $(\mathrm{R})$ to form the complex (RL) is described by Equation 5 .

$$
\Delta G=G(\mathrm{RL})-G(\mathrm{~L})-G(\mathrm{R})
$$

The free energy of individual species in Equation 1 is given by Equation 6.

$$
G(\mathrm{X})=H(\mathrm{X})-T S(\mathrm{X}), \text { and hence } G(\mathrm{X})=U(\mathrm{X})+\mathrm{PV}(\mathrm{X})-T S(\mathrm{X})
$$

The method is frequently described in the literature. ${ }^{30}$

\section{Acknowledgements}

This work was supported from project CZ.1.07/2.3.00/30.0024 "Development of research teams of R\&D projects at the Technical University of Liberec", project LO1201 of the Ministry of Education, Youth and Sports in the framework of the targeted support of the "National Programme for Sustainability I" and the OPR\&DI project "Centre for Nanomaterials, Advanced Technologies and Innovation CZ.1.05/2.1.00/01.0005". We also give special thanks to Professor D. Case for providing us with a waiver license for AMBER and The Scientific and Technological Research Council of Turkey (TUBITAK) for computer facilities.

\section{References}

1. $\quad$ Breslow, R.; Dong, S. D. Chem. Rev. 1998, 98, 1997-2012. http://pubs.acs.org/doi/abs/10.1021/cr970011j?journalCode=chreay

2. Marinescu, L.; Bols, M. Trends Glycosci. Glycotechnol. 2009, 21, 309-323. https://www.jstage.jst.go.jp/article/tigg/21/122/21_122_309/_article

3. Řezanka, P.; Navrátilová, K.; Řezanka, M.; Král, V.; Sýkora, D. Electrophoresis 2014. 35, 2701-2721. http://onlinelibrary.wiley.com/doi/10.1002/elps.201400145/full

4. Zhang, X.; Zhang, C.; Sun, G.; Xu, X.; Tan, Y.; Wu, H.; Cao, R.; Liu, J.; Wu, J. C. A Review. Instrum. Sci. Technol. 2012, 40, 194-215. 
http://www.tandfonline.com/doi/abs/10.1080/10739149.2011.651675\#.VxXf9vmLRdg

5. $\quad$ Rekharsky, M. V.; Inoue, Y. Chem. Rev. 1998, 98, 1875-1918. http://pubs.acs.org/doi/abs/10.1021/cr970015o?journalCode=chreay

6. Machida, Y.; Kagawa, M.; Nishi, H. J. Pharm. Biomed. Anal. 2003, 30, 1929-1942. http://www.sciencedirect.com/science/article/pii/S073170850200537X

7. Izatt, R. M.; Wang, T.; Hathaway, J. K.; Zhang, X. X.; Curtis, J. C.; Bradshaw, J. S.; Zhu, C. Y.; Huszthy, P. J. Incl. Phenom. Mol. Recognit. Chem. 1994, 17, 157-175. http://link.springer.com/article/10.1007/BF00711856\#page-1

8. El-Barghouthi, M. I.; Jaime, C.; Al-Sakhen, N. A.; Issa, A. A.; Abdoh, A. A.; Al Omari, M. M.; Badwan, A. A.; Zughul, M. B. J. Mol. Struct.-Theochem. 2008, 853, 45-52. http://www.sciencedirect.com/science/article/pii/S0166128007007749

9. El-Barghouthi, M. I.; Jaime, C.; Akielah, R. E.; Al-Sakhen, N. A.; Masoud, N. A.; Issa, A. A.; Badwan, A. A.; Zughul, M. B. Supramol. Chem. 2009, 21, 603-610. http://www.tandfonline.com/doi/abs/10.1080/10610270802613562

10. Choi, Y.; Jung, S. Carbohydr. Res. 2004, 339, 1961-1966. http://www.sciencedirect.com/science/article/pii/S0008621504002423

11. Núñez-Agüero, C.-J.; Escobar-Llanos, C.-M.; Díaz, D.; Jaime, C.; Garduño-Juárez, R. Tetrahedron 2006, 62, 4162-4172.

http://www.sciencedirect.com/science/article/pii/S0040402006002110

12. Srinivasan, J.; Cheatham, T. E.; Cieplak, P.; Kollman, P. A.; Case, D. A. J. Am. Chem. Soc. 1998, 120, 9401-9409.

http://www.sciencedirect.com/science/article/pii/S0040402006002110

13. Durdagi, S.; Zhao, C.; Cuervo, J. E.; Noskov, S. Y. Curr. Med. Chem. 2011, 18, 26012611.

http://www.ingentaconnect.com/content/ben/cmc/2011/00000018/00000017/art00008

14. (a) Connors, K. A. Binding Constants: the Measurements of Molecular Complex Stability. Wiley : New York; 1987.

(b) Benesi, H. A.; Hildebrand, J. H. A J. Am. Chem. Soc. 1949, 71, 2703. http://pubs.acs.org/doi/abs/10.1021/ja01176a030

15. Wang, J.; Ueno, A. Macromol. Rapid Commun. 2000, 21, 887-890. http://onlinelibrary.wiley.com/doi/10.1002/1521-3927(20000801)21:13\%3C887::AIDMARC887\%3E3.0.CO;2-U/abstract

16. Popr, M.; Hybelbauerova, S.; Jindrich, J. Beilstein J. Org. Chem. 2014, 10, 1390-1396. http://www.beilstein-journals.org/bjoc/content/html/1860-5397-10-142.html

17. Bonnet, V.; Duval, R.; Tran, V.; Rabiller, C. Eur. J. Org. Chem. 2003, 4810-4818. http://onlinelibrary.wiley.com/doi/10.1002/ejoc.200300449/full

18. Case, D. A.; Darden, T. A.; Cheatham III, T.E.; Simmerling, C.; Wang, J.; Duke, R.E.; Luo, R.; Walker, R. C.; Zhang, W.; Merz, K. M.; Roberts, B.P.; Hayik, S.; Roitberg, A.; Seabra, G.; Kolossváry, I., Wong, K. F.; Paesani, F.; Vanicek, J.; Liu, J.; Wu, X.; Brozell, S. R.; Steinbrecher, T.; Gohlke, H.; Cai, Q.; Ye, X.; Wang, J.; Hsieh, M. J.; Cui, G.; Roe, 
D. R.; Mathews, D. H.; Seetin, M. G.; Sagui, C.; Babin, V.; Luchko, T.; Gusarov, S.; Kovalenko, A.; Kollman, P. A. Amber 11 Users, Manual. University of California, San Francisco, 2010. http://infoscience.epfl.ch/record/150146/files/Amber11.pdf

19. Syson, K.; Stevenson, C. E. M.; Rejzek, M.; Fairhurst, S. A.; Nair, A.; Bruton, C. J.; Field, R. A.; Chater, K. F.; Lawson, D. M.; Bornemann, S. J. Biol. Chem. 2011, $28638298-$ 38310.

http://www.jbc.org/content/286/44/38298.short

20. Accelrys Software Inc., Discovery Studio Modeling Environment, Release 4.0, San Diego: Accelrys Software Inc. 2013. http://pubs.rsc.org/en/content/articlelanding/2012/cc/c2cc38067f/unauth\#!divAbstract

21. Kirschner, K. N.; Yongye, A. B.; Tschampel, S. M.; Outeirino, J. G.; Daniels, C. R.;

Foley, B. L.; Woods, R. J. J. Comp. Chem. 2008, 29, 622-655. http://onlinelibrary.wiley.com/doi/10.1002/jcc.20820/full

22. Jakalian, A.; Jack, D. B.; Bayly, C. I. J. Comput. Chem. 2002, 23, 1623-1641. http://onlinelibrary.wiley.com/doi/10.1002/jcc.10128/full

23. (a) Lee, M. C.; Duan, Y. Struc. Func. Bioinfo. 2004, 55, 620-634. http://onlinelibrary.wiley.com/doi/10.1002/prot.10470/full

(b) Wang, J.; Wolf, R. M.; Caldwell, J. W.; Kollman, P. A.; Case, D. A. J. Comput. Chem. 2004, 25, 1157-1174.

http://onlinelibrary.wiley.com/doi/10.1002/jcc.20035/full

24. Kollman, P. A.; Massova, I.; Reyes, C.; Kuhn, B.; Huo, S.; Lee, M.; Duan, T. Y.; Wang, W.; Donini, O.; Cieplak, P.; Srinivasan, J.; Case, D. A. Chem. Res. 2000, 33, 889-897. http://pubs.acs.org/doi/abs/10.1021/ar000033j

25. Pettersen, E. F.; Goddard, T. D.; Huang, C. C.; Couch, G. S.; Greenblatt, D. M.; Meng, E. C.; Ferrin, T. E. J. Comput. Chem. 2004, 25, 1605-1612. http://onlinelibrary.wiley.com/doi/10.1002/jcc.20084/full

26. Cornell, W. D.; Cieplak, P.; Bayly, C. I.; Gould, I. R.; Merz, K. M.; Ferguson, D. M.; Spellmeyer, D. C.; Fox, T.; Caldwell, J. W.; Kollman, P. A. J. Am. Chem. Soc. 1995, 117, 5179-5197. http://pubs.acs.org/doi/abs/10.1021/ja00124a002

27. Darden, T.; York, D.; Pedersen, L. J. Chem. Phys. 1993, 98, 10089-10092. http://scitation.aip.org/content/aip/journal/jcp/98/12/10.1063/1.464397

28. Kollman, P. A.; Massova, I.; Reyes, C.; Kuhn, B.; Huo, S.; Chong, L.; Lee, M.; Lee, T.; Duan, Y.; Wang, W. Acc. Chem. Res. 2000, 33, 889-897. http://pubs.acs.org/doi/abs/10.1021/ar000033j

29. Srinivasan, J.; Cheatham, T. E.; Cieplak, P.; Kollman, P. A.; Case, D. A. J. Am. Chem. Soc. 1998, 120, 9401-9409.

http://pubs.acs.org/doi/abs/10.1021/ja981844+ 
30. Ercan, S.; Arslan, N.; Kocakaya, S. O.; Pirinccioglu, N.; Williams, A. J. Mol. Model. 2014, 20, 2096-2110.

http://link.springer.com/article/10.1007/s00894-014-2096-9\#/page-1

31. Samu, E.; Huszthy, P.; Horvath, G.; Szollosy, A.; Neszmelyi, A. Tetrahedron: Asymmetry. 1999, 10, 3615-3626.

http://www.sciencedirect.com/science/article/pii/S095741669900381X

32. Foster, R.; Fyfe, C. A. Prog. Nucl. Magn. Reson. Spectrosc. 1969, 4, 1-89. http://www.sciencedirect.com/science/article/pii/002223649290144V

33. Izatt, R. M.; Wang, T.; Hathaway, J. K.; Zhang, X. X.; Curtis, J. C.; Bradshaw, J. S.; Zhu, C. Y.; Huszthy, P. J. Incl. Phenom. Macrocycl. Chem. 1994, 17, 157-175. http://link.springer.com/article/10.1007/BF00711856\#page-1 